\title{
Vitamin E succinate induces apoptosis via the PI3K/AKT signaling pathways in EC109 esophageal cancer cells
}

\author{
PENG YANG ${ }^{1,2}$, JIAYING ZHAO ${ }^{1}$, LIYING HOU ${ }^{3}$, LEI YANG $^{1}$, KUN WU $^{3}$ and LINYOU ZHANG ${ }^{1}$ \\ ${ }^{1}$ Department of Thoracic Surgery, The Second Affiliated Hospital of Harbin Medical University, Harbin, Heilongjiang 150086; \\ ${ }^{2}$ Department of Cardiothoracic Surgery, Daqing Oilfield General Hospital, Daqing, Heilongjiang 163000; \\ ${ }^{3}$ Department of Nutrition and Food Hygiene, Harbin Medical University, Harbin, Heilongjiang 150081, P.R. China
}

Received June 20, 2015; Accepted June 14, 2016

DOI: $10.3892 / \mathrm{mmr} .2016 .5445$

\begin{abstract}
Esophageal cancer is the fourth most common gastrointestinal cancer, it generally has a poor prognosis and novel strategies are required for prevention and treatment. Vitamin E succinate (VES) is a potential chemical agent for cancer prevention and therapy as it exerts anti-tumor effects in a variety of cancers. However, the role of VES in tumorigenesis and progression of cancer remains to be elucidated. The present study aimed to determine the effects of VES in regulating the survival and apoptosis of human esophageal cancer cells. EC109 human esophageal cancer cells were used to investigate the anti-proliferative effects of VES. The MTT and Annexin V-fluorescein isothiocyanate/propidium iodide assays demonstrated that VES inhibited cell proliferation and induced apoptosis in esophageal cancer cells. Furthermore, VES downregulated constitutively active basal levels of phosphorylated (p)-serine-threonine kinase AKT (AKT) and p-mammalian target of rapamycin (mTOR), and decreased the phosphorylation of AKT substrates Bcl-2-associated death receptor and caspase-9, in addition to mTOR effectors, ribosomal protein S6 kinase $\beta 1$ and eIF4E-binding protein 1. Phosphoinositide-3-kinase (PI3K) inhibitor, LY294002 suppressed p-AKT and p-mTOR, indicating PI3K is a common upstream mediator. The apoptosis induced by VES was increased by inhibition of AKT or mTOR with their respective inhibitor in esophageal cancer cells. The results of the present study suggested that VES targeted the PI3K/AKT signaling pathways and induced apoptosis in esophageal cancer cells. Furthermore, the current study suggests that VES may be useful in a combinational therapeutic strategy employing an mTOR inhibitor.
\end{abstract}

Correspondence to: Dr Linyou Zhang, Department of Thoracic Surgery, The Second Affiliated Hospital of Harbin Medical University, 246 Xuefu Road, Harbin, Heilongjiang 150086, P.R. China

E-mail: zhlinyou@yeah.net

Key words: esophageal cancer, vitamin E succinate, apoptosis, PI3K, AKT, mTOR

\section{Introduction}

Esophageal cancer is the eighth leading cause of cancer globally with 456,000 new cases diagnosed in 2012 (1). It resulted in 345,000 mortalities in 1990 and 400,000 in $2012(1,2)$. Rates of diagnosis vary widely among countries, with $\sim 50 \%$ of all cases occurring in China. It is $\sim 3$ times more common in men than in women (1). The two predominant sub-types of esophageal cancer are squamous cell carcinoma and adenocarcinoma. Squamous cell carcinoma arises from the epithelial cells that line the esophagus (3), while adenocarcinoma arises from glandular cells present in the lower third of the esophagus, often following a prior transformation into an intestinal cell type as part of a condition termed Barrett's esophagus) $(1,4)$. Surgical resection and adjuvant therapy are used to treat esophageal cancer, however, patients often have a poor prognosis with a 5-year survival rate of $\sim 13-18 \%(5,6)$. The high mortality rate for esophageal cancer is predominantly a result of the advanced stage at diagnosis in the majority of cases, by the time of diagnosis, $80 \%$ of esophageal cancers are no longer localized to the esophagus. Thus, the development of effective therapeutic strategies is required. Dietary modulation of signaling pathways is a promising strategy for cancer prevention and treatment. Vitamin Es, including tocopherols and tocotrienols, exhibit natural antioxidant activity. Vitamin E succinate (VES) or $\alpha$-tocopheryl succinate, is obtained by esterification of $\alpha$-tocopherol and has been reported to inhibit growth and induce apoptosis in a variety of types of cancer (7-9), including prostate, breast, gastric, and colorectal cancer, in addition to melanomas (10-13).

Previous studies have demonstrated that activation of the phosphoinositide-3-kinase (PI3K), serine-threonine kinase AKT (AKT) and mammalian target of rapamycin (mTOR) may be important in cell proliferation and apoptosis (14). They are constitutively activated or overexpressed in numerous types of cancer, and result in cancer progression via stimulating cellular proliferation and suppressing cell death signaling pathways (15). PI3K promotes tumor cell survival by triggering the activation of downstream mediators of AKT (16). AKT exerts its effects via a diverse array of effectors, which regulate key cellular processes, including transcription, translation, apoptosis and cell cycle progression (17). AKT directly controls apoptosis by inducing phosphorylation and inactivation of 
pro-apoptotic proteins, including Bcl-2-associated death receptor (Bad) and caspase-9 (18-20). In addition, a major downstream substrate of AKT is the serine/threonine kinase mTOR. mTOR is directly activated by AKT via phosphorylated at Ser2448, and can be indirectly activated by phosphorylation and inactivation of tuberous sclerosis complex 2, also termed tuberin, by AKT. The raptor-mTOR complex substrates, ribosomal protein S6 kinase $\beta 1$ (p70S6K) and the eIF4E-binding protein 1 (4E-BP1), modulate transcription and translation to selectively regulate downstream proteins that control cell survival and death (21).

It has been reported that VES exerts its apoptotic effect in cancer cells via multiple apoptotic signaling pathways. VES regulates transforming growth factor- $\beta$ (TGF- $\beta$ ) and Fas (CD95) signaling pathways, thus, stimulating c-Jun N-terminal kinase-induced apoptosis (22). In addition, TGF- $\beta$-independent apoptotic mechanisms have also been demonstrated (23). Reactive oxygen species generated by mitocans mediate the formation of mitochondrial outer membrane channels by activating Bcl-2-associated X protein channels allowing translocation of cytochrome $c$ into the cytoplasm and activation of caspase-3 and -9 , which is a key mechanism in VES-induced apoptosis (8). The present study demonstrated that VES induced apoptosis in esophageal cancer cells via targeting the PI3K/AKT signaling pathways and modulating the downstream effectors Bad and caspase-9, in addition to mTOR. The results suggested that VES in combination with AKT or mTOR inhibitors may be an effective therapeutic strategy for esophageal cancer.

\section{Materials and methods}

Chemicals. VES was purchased from Sigma-Aldrich (St. Louis, MO, USA). A PI3K inhibitor, LY294002, and AKT inhibitor, triciribine, were purchased from Cell Signaling Technology, Inc. (Danvers, MA, USA). mTOR inhibitor, rapamycin, was purchased from EMD Millipore (Billerica, MA, USA).

Cell culture. The EC109 human esophageal squamous cell carcinoma cell line was obtained from the Cell Bank of the Chinese Academy of Science (Shanghai, China). EC109 cells were cultured in Dulbecco's modified Eagle's medium (Gibco; Thermo Fisher Scientific, Inc., Waltham, MA, USA) containing $10 \%$ fetal bovine serum (Lonza Group, Ltd., Basel, Switzerland) and $1 \%$ penicillin/streptomycin (complete media) at $37^{\circ} \mathrm{C}$ in a humidified $5 \% \mathrm{CO}_{2}$ incubator.

Western blotting. Cells were washed with phosphate-buffered saline and lysed in lysis buffer (50 mM HEPES, pH 8.0; $1 \%$ Triton X-100; 1.5 mM EDTA; $150 \mathrm{mM} \mathrm{NaCl} ; 1 \mathrm{mM} \mathrm{Na}_{3} \mathrm{VO}_{4}$; $50 \mathrm{mM} \mathrm{NaF} ; 1 \mathrm{mM} \mathrm{MgCl} ; 20 \mathrm{mM} \beta$-glycerophosphate; $10 \%$ glycerol; $1 \mu \mathrm{M}$ pepstatin $\mathrm{A} ; 1 \mathrm{mM}$ phenylmethylsulphonyl fluoride; and $10 \mu \mathrm{g} / \mathrm{ml}$ aprotonin). Cell lysate was centrifuged at $10,000 \mathrm{x}$ g for $10 \mathrm{~min}$ and the supernatant was collected. Protein samples were quantified using a bicinchoninic acid protein assay kit (Beyotime Institute of Biotechnology, Haimen, China). Total protein samples (20-50 $\mu \mathrm{g}$ ) were separated by $12 \%$ SDS-PAGE and transferred to nitrocellulose membranes (GE Healthcare Life Sciences, Chalfont, UK). The membranes were blocked with $5 \%$ bovine serum albumin (Sigma Aldrich) in Tris-buffered saline Tween 20 (TBST) for $1 \mathrm{~h}$, and incubated with specific primary antibodies overnight at $4^{\circ} \mathrm{C}$. Subsequently, the membranes were washed 3 times with TBST, followed by incubation with horseradish peroxidase (HRP)-conjugated secondary antibodies for $2 \mathrm{~h}$ at room temperature. Antibodies against the following proteins were used: Rabbit polyclonal anti-AKT (1:1,000; cat. no. 9272), Bad (1:1,000; cat. no. 9292), casapse 9 (1:1,000; cat. no. 9502), phosphorylated (p)-mTOR (Ser2448; 1:1,000; cat. no. 2971); rabbit monoclonal anti-p-AKT (Ser473, 1:2,000, cat. no. 4060; and Thr308, 1:1,000, cat. no. 13038), p-Bad (Ser136; 1:1,000; cat. no. 4366), mTOR (1:1,000; cat.no. 2983), p70S6K (1:1,000; cat. no. 2708) 4E-BP1 (1:1,000; cat. no. 9644), p-4E-BP1 (Thr37/46; 1:1,000; cat. no. 2855) and GAPDH (1:1,000; cat. no. 2118); mouse monoclonal anti-p-p70S6K (Thr389; 1:1,000, cat. no. 9206) (all obtained from Cell Signaling Technology, Inc.); and goat polyclonal anti-p-caspase 9 (Ser196; 1:500; cat. no. sc11755; Santa Cruz Biotechnology, Inc., Dallas, TX, USA). HRP-conjugated goat anti-rabbit secondary antibody (1:2,000; cat. no. 7074; Cell Signaling Technology, Inc.), horse anti-mouse antibody (1:2,000; cat. no. 7076; Cell Signaling Technology, Inc.) and donkey anti-goat antibody (1:5,000; cat. no. sc2020; Santa Cruz Biotechnology, Inc.) were used. Enhanced chemiluminescence-detecting reagent (GE Healthcare Life Sciences) was used for development. The protein blots were quantified by densitometry using QuantityOne software (version 4.5.0; Bio-Rad Labroatories, Inc., Hercules, CA, USA) and the amounts were expressed relative to the corresponding reference protein.

Cell survival assay. Cell survival was evaluated using the MTT assay. Cells were seeded at a density of $1 \times 10^{4} /$ well in a 96-well flat bottom plate. Cells were allowed to grow in a $37^{\circ} \mathrm{C}$, $5 \% \mathrm{CO}_{2}$ incubator for $48 \mathrm{~h}$, and then $20 \mu \mathrm{l}$ of $5 \mathrm{mg} / \mathrm{ml} \mathrm{MTT}$ was added to each well for a further $4 \mathrm{~h}$. Cells were washed by phosphate-buffered saline and lysed by addition of $200 \mu \mathrm{l}$ dimethyl sulfoxide. Absorbance was detected at a wavelength of $490 \mathrm{~nm}$ using an enzyme-linked immunosorbent assay reader.

Quantification of apoptosis. Apoptosis was quantified using the Annexin V-fluorescein isothiocyanate (FITC)/propidium iodide (PI) assay (Sigma-Aldrich) following the manufacturer's protocols. The Annexin V-FITC/PI assay detects the amount of phosphatidylserine on the outer surface of the plasma membrane, a biochemical alteration observed in membranes of apoptotic cells, and the amount of PI, a dye that easily enters dead cells or cells in the late stages of apoptosis and binds DNA. Fluorescence was detected using a FACSCalibur flow cytometer (BD Biosciences, Franklin Lakes, NJ, USA) by fluorescence-activated cell sorting (FACS) analysis, and data were analyzed using CellQuest software (version 7.5.3; BD Biosciences). Cells with phosphatidylserine on their surface were considered to be apoptotic.

Statistical analysis. Data are presented as the mean \pm standard error of the mean and all the experiments were replicated at least 3 times. SPSS software (version 11.0; SPSS, Inc., Chicago, IL, USA) was used to perform statistical analysis. A Student's 


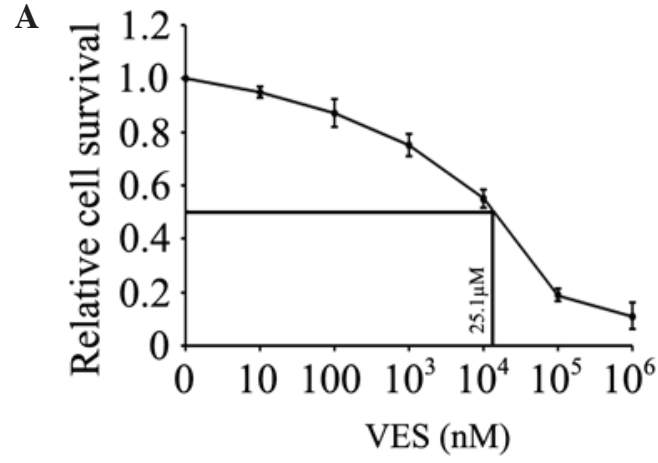

B

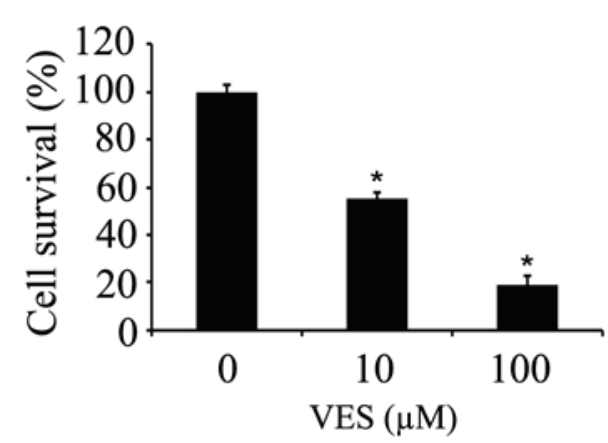

Figure 1. VES inhibits the proliferation of EC-109 esophageal cancer cells (A) Cells $\left(1 \times 10^{4}\right)$ were plated in 96-well plates containing $100 \mathrm{ml}$ medium. Following incubation for $24 \mathrm{~h}$, the cells were treated with varying concentrations of VES for $24 \mathrm{~h}$ and cell survival was evaluated using the MTT assay. (B) Cell viability was evaluated by MTT assay and presented as the mean \pm standard deviation compared with untreated control cells. " $\mathrm{P}<0.05$ vs. $0 \mu \mathrm{M}$ VES group. VES, vitamin E succinate.

t-test was used to compare treated and untreated cells. $\mathrm{P}<0.05$ was considered to indicate a statistically significant difference.

\section{Results}

VES inhibits the proliferation of esophageal cancer cells. The effects of VES on the EC109 human esophageal cancer cell line was detected in the present study. The $\mathrm{IC}_{50}$ value of VES was determined by treating EC109 cells with increasing concentrations of VES for $24 \mathrm{~h}$. $\mathrm{IC}_{50}$ value was calculated to be $25.1 \mu \mathrm{M}$ for EC109 cells at $24 \mathrm{~h}$ (Fig. 1A). EC109 cells were treated with $10-100 \mu \mathrm{M}$ VES for $24 \mathrm{~h}$, and the cell viability was evaluated by MTT assay. The results demonstrated that the growth was decreased by $\sim 45$ and $\sim 81 \%$ following treatment with 10 and $100 \mu \mathrm{M}$ VES in EC109 cells (Fig. 1B). The current study also investigated whether the proliferation inhibition resulted from the induction of apoptosis in the cells.

VES induces the apoptosis of esophageal cancer cells. To investigate whether VES promotes apoptosis in esophageal cancer cells, EC109 cells were treated with VES at various concentrations $(0,10$ or $100 \mu \mathrm{M}$; Fig. $2 \mathrm{~A})$ or for different periods of time (12, 24 or 48 h; Fig. 2B). Apoptosis was quantified by FACS analyses. Apoptosis in the EC109 cells was induced by 10 or $100 \mu \mathrm{M}$ VES treatment for $24 \mathrm{~h}$ in a dose-dependent manner (Fig. 2A). Apoptosis of EC109 cells was induced by $25 \mu \mathrm{M}$ VES for 12, 24 and $48 \mathrm{~h}$ in a time-dependent manner (Fig. 2B). These results suggest that VES is a potent inducer of apoptosis in EC109 esophageal cancer cells.
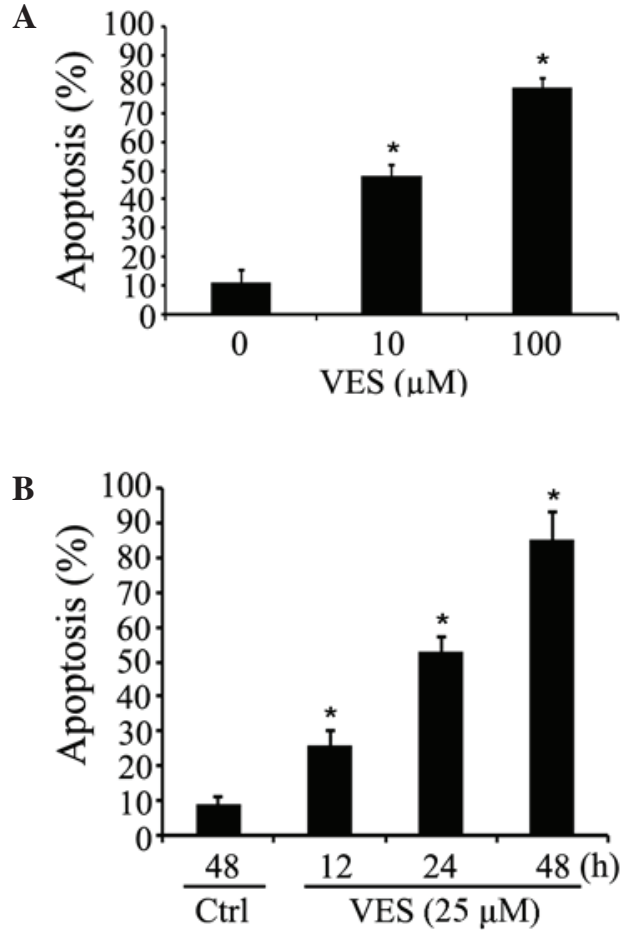

Figure 2. VES induces apoptosis in human esophageal cancer cells in a dose- and time-dependent manner. (A) EC-109 cells were treated with different concentrations of VES for $24 \mathrm{~h}$ and the apoptosis induced by VES was determined by FACS assay. ${ }^{*} \mathrm{P}<0.05$ vs. VES treatment group. (B) Cells were treated with $25 \mu \mathrm{M}$ VES for different times, and untreated control cells were cultured for $48 \mathrm{~h}$. The apoptosis induced by VES was assessed by FACS assay. Data are presented as the mean \pm standard error of the mean ${ }^{*} \mathrm{P}<0.05$ vs. ctrl group. VES, vitamin E succinate; FACS, fluorescence-activated cell sorting; Ctrl, control.

VES suppresses the active forms of AKT and mTOR in esophageal cancer cells. EC109 cells that are not treated with VES express high levels of p-AKT, and downstream substrates p-Bad and p-caspase-9 (Fig. 3). EC109 cells were treated with $25 \mu \mathrm{M}$ VES for 12,24 and $48 \mathrm{~h}$, which reduced levels of p-AKT (Ser473/Thr308), p-Bad (Ser136), and p-caspase-9 (Ser196) in a time-dependent manner (Fig. 3A and C). It also downregulated p-mTOR (Ser2448) and its substrates p-p70S6K (Thr389) and p-4E-BP1 (Thr37/46; Fig. 3B and C). These data demonstrated that VES reduced the levels of active AKT, mTOR, and their downstream effectors, promoting the activation of Bad and caspase-9, which mediate cell apoptosis.

PI3K inhibitor, LY294002 reduces phosphorylation of AKT and mTOR in EC109 cells. To investigate the underlying mechanisms of regulation of the levels of p-AKT and p-mTOR, EC109 cells were treated with $2 \mu \mathrm{M}$ PI3K inhibitor LY294002 for $12 \mathrm{~h}$. LY294002 decreased the p-AKT and its substrates p-Bad (Ser136) and p-caspase-9 (Ser196; Fig. 4A), in addition to p-mTOR (Ser2448) and its substrate p-p70S6 K (Thr389) (Fig. 4B). This indicates that PI3K is a key contributor to regulations of $\mathrm{p}-\mathrm{AKT}$ and $\mathrm{p}-\mathrm{mTOR}$.

VES cooperated with inhibitors of PI3K, AKT and mTOR to induce apoptosis. To investigate the effects of inhibition of members of PI3K signaling pathway on VES-induced apoptosis, EC109 cells were treated with $15 \mu \mathrm{M}$ VES plus 
A

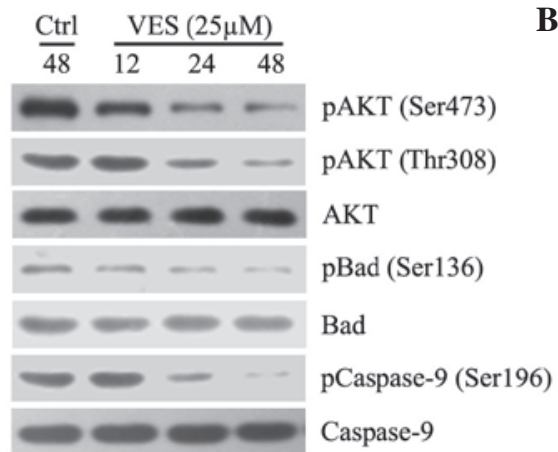

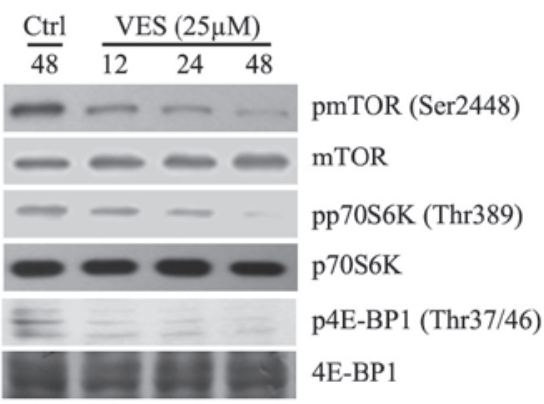

C

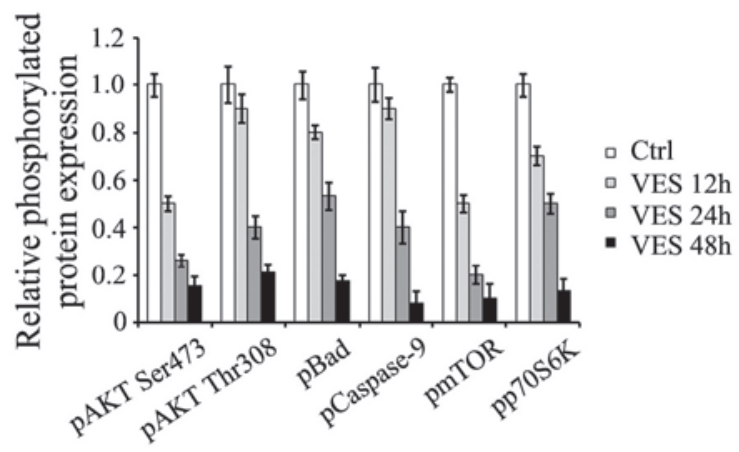

Figure 3. VES inhibits AKT and mTOR, in addition to their downstream targets. EC-109 cells were treated with $25 \mu \mathrm{M}$ VES for 12, 24 and $48 \mathrm{~h}$. (A) Protein expression levels of p-AKT (Ser473 and Thr308), p-Bad (Ser136), p-caspase-9 (Ser196), and expression levels of total AKT, Bad and caspase-9 were detected by western blotting. (B) Protein expression levels of p-mTOR (Ser2448), p-p70S6K (Thr389), and p-4E-BP1 (Thr37/46), and expression levels of total mTOR, p70S6 K and 4E-BP1 were determined by western blotting. (C) Protein expression levels were quantified and presented as the mean \pm standard error of the mean. VES, vitmain E succinate; AKT, serine-threonine kinase AKT; mTOR, mammalian target of rapamycin; p, phosphorylated; Bad, Bcl-2-associated death promoter; p70S6K, ribosomal protein S6 kinase $\beta 1$; 4E-BP1, eIF4E-binding protein 1; Ctrl, control.

A

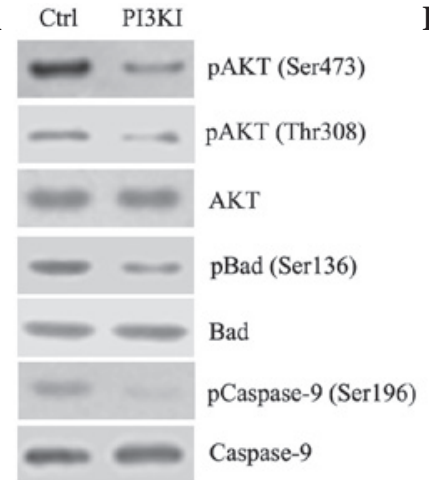

Figure 4. AKT and mTOR are downstream targets of PI3K. EC109 cells were treated with $2 \mu \mathrm{M}$ PI3K inhibitor (PI3KI) LY294002 for $12 \mathrm{~h}$. (A) Protein expression levels of p-AKT (Ser473), p-Bad (Ser136) and p-caspase-9 (Ser196), and expression levels of total AKT, Bad and caspase-9 were determined by western blotting. (B) Protein expression levels of p-mTOR (Ser2448) and p-p70S6K (Thr389), and total levels of mTOR and p70S6K were also determined by western blotting. PI3K, phosphoinositide-3-kinase; AKT, serine-threonine kinase AKT; mTOR, mammalian target of rapamycin; p, phosphorylated; Bad, Bcl-2-associated death promoter; p70S6K, ribosomal protein S6 kinase $\beta 1$; Ctrl, control.

$2 \mu \mathrm{M} \mathrm{LY} 294002,10 \mu \mathrm{M} \mathrm{AKT}$ inhibitor triciribine, and $50 \mathrm{nM}$ mTOR inhibitor rapamycin for $24 \mathrm{~h}$. Single treatments with VES or inhibitors induced apoptosis, whereas VES combined with each inhibitor individually markedly increased the induction of apoptosis compared with single treatments (Fig. 5A). VES and the PI3K inhibitor decreased the expression levels of $\mathrm{p}-\mathrm{AKT}$ and $\mathrm{p}$-mTOR, and the combination of VES + PI3K inhibitor synergistically decreased expression levels of $\mathrm{p}-\mathrm{AKT}$ and $\mathrm{p}$-mTOR in comparison with individual treatments or the control (Fig. 5B). AKT and mTOR inhibitors increased VES downregulation of p-AKT and p-mTOR, respectively (Fig. 5C). These data indicate that VES inhibited the activation of AKT and mTOR, and may function with the inhibitors of AKT and mTOR to promote esophageal cancer cell apoptosis.

$V E S$ blocked the increase of $p$-AKT induced by the $m T O R$ inhibitor. It has been indicated that the increase in expression of p-AKT may be induced by the mTOR inhibitor rapamycin via negative feedback regulation of insulin receptor substrate $(24,25)$. As expected, the mTOR inhibitor induced an increase in expression of p-AKT, which attenuates its anti-cancer efficacy. Notably, mTOR inhibitor treatment combined with VES was able to suppress this counterproductive effect in AKT, which is a pro-survival mediator (Fig. 5D).

\section{Discussion}

VES exhibits anti-tumor activity in colorectal, breast, prostate, skin, and gastric cancer by inducing various apoptotic signaling pathways. The results of the present study demonstrated that VES inhibited cell proliferation and induced apoptosis in EC109 esophageal cancer cells. To the best of our knowledge, the present study is the first to indicate that VES inhibited AKT-mediated anti-apoptotic events by suppressing phosphorylation of Bad and caspase-9. In addition, VES suppressed AKT and downregulated mTOR activity, resulting in 
A

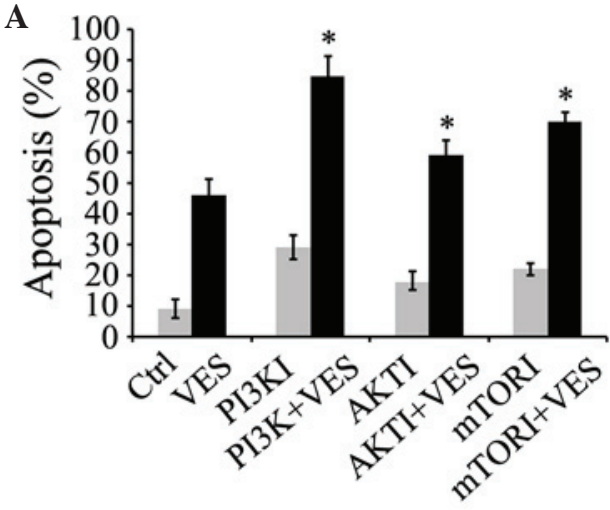

C
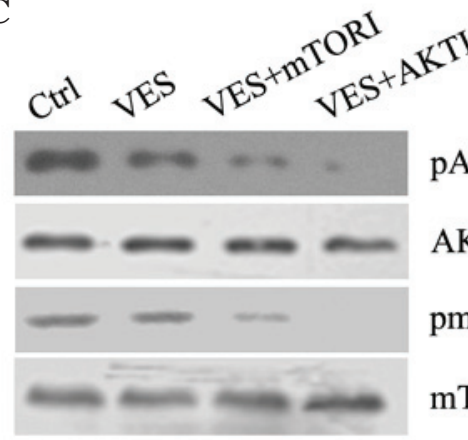

AKT

mTOR
pAKT (Ser473)

B

Ctrl VES PI3KI VES+PI3KI

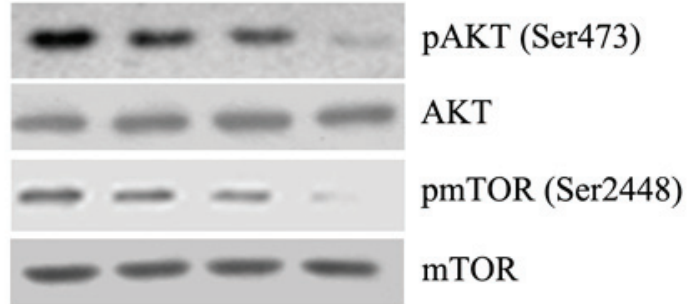

D

Ctrl mTORI mTORI+VES

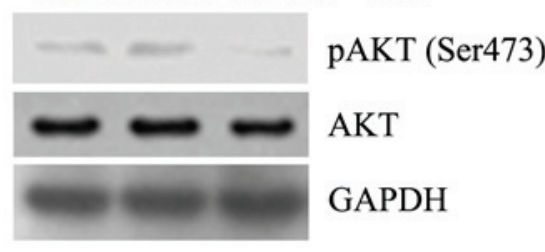

pmTOR (Ser2448)

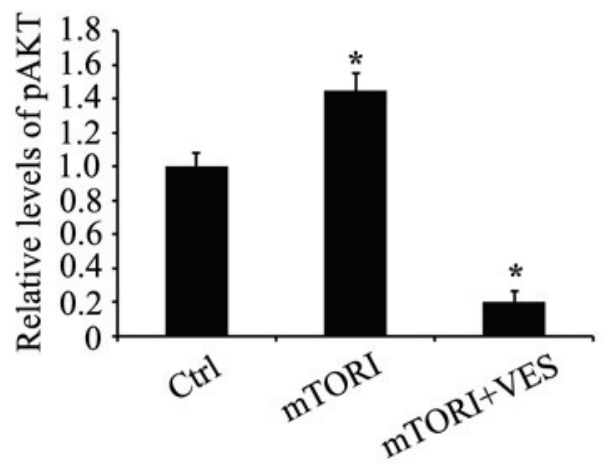

Figure 5. Inhibitors of PI3K, AKT and mTOR enhance VES-induced apoptosis. (A) EC109 cells were cultured with $15 \mu \mathrm{M}$ VES, plus $2 \mu \mathrm{M}$ PI3KI, LY294002, $10 \mu \mathrm{M}$ AKTI, triciribine, and $50 \mathrm{nM}$ mTORI, rapamycin for $24 \mathrm{~h}$. Apoptosis was determined by fluorescence-activated cell sorting analysis. (B and C) Protein levels of p-AKT (Ser473) and p-mTOR (Ser2448), in addition to expression levels of total AKT and mTOR were determined by western blot analyses in EC109 cells treated with the three inhibitors and VES. (D) EC109 cells were treated with $50 \mathrm{nM}$ mTORI rapamycin and $15 \mu \mathrm{M}$ VES for $24 \mathrm{~h}$. Protein expression levels of p-AKT (Ser473), AKT and GAPDH were determined by western blot analyses. Protein expression levels were quantified and presented as the mean \pm standard error of the mean. "P<0.05 vs. ctrl group. PI3K, phosphoinositide-3-kinase; AKT, serine-threonine kinase AKT; mTOR, mammalian target of rapamycin; VES, vitamin E succinate; p, phosphorylated; PI3KI, PI3K inhibitor; AKTI, AKT inhibitor; mTORI, mTOR inhibitor; Ctrl, control.

reductions of downstream effectors, p-p70S6K and p-4E-BP1. The present study hypothesized that VES induced apoptosis by inhibiting PI3K/AKT signaling pathways, which stimulated activation of Bad and caspase-9. Furthermore, it was indicated that the side-effect of the mTOR inhibitors, namely, activation of AKT, was prevented by combination treatment with VES. These results demonstrated that VES induced apoptosis via inhibition of the PI3K/AKT signaling pathways and suppressed the mTOR inhibitor-mediated activation of AKT, suggesting that combination treatment an mTOR inhibitor and VES may improve clinical treatment outcome.

PI3K/AKT signaling is constitutively activated in numerous types of human cancer. Activation of this signaling in cancer cells has been associated with cancer cell viability, tumor growth and drug resistance. Thus, PI3K/AKT signaling has attracted growing attention as a potential target for cancer therapeutic strategies. Downregulation of PI3K/AKT signaling in cancer cells results in cellular apoptosis and sensitization to chemotherapy $(26,27)$. Various strategies using genetic and pharmacologic inhibitors to inhibit anti-apoptotic proteins, including X-linked inhibitor of apoptosis protein, survivin, inhibitor of apoptosis proteins, matrix metalloproteinases, B-cell lymphoma 2 (Bcl-2), nuclear factor- $\kappa \mathrm{B}$ and AKT have been used to sensitize cancer cells to chemotherapy and apoptosis $(27,28)$. $\alpha$-Tocopherol ether-linked acetic acid $(\alpha$-TEA) suppresses AKT and contributes to $\alpha$-TEA-induced apoptosis in prostate and ovarian cancer cells $(29,30)$. The present study demonstrated that inhibition of PI3K/AKT signaling potentiates VES-induced apoptosis in esophageal cancer cells.

Bad and caspase-9 are pro-apoptotic proteins. Bad is a member of the Bcl-2 family, which accelerates apoptosis via the formation of heterodimers with pro-survival factors, Bcl-2 and B-cell lymphoma-extra large (Bcl-xL). Phosphorylation of Bad at Ser112 and Ser136 blocks its binding with Bcl-2 or Bcl-xL, promoting cell growth $(31,32)$. The phosphorylation of $\mathrm{Bad}$ has been reported to be enhanced by extracellular signal-regulated kinase/ribosomal protein S6 kinase $\alpha-1$ and PI3K/AKT signaling pathways, respectively (32). The current study demonstrated that VES suppressed phosphorylation of Bad at Ser136, suggesting that downregulation of AKT activity mediated by VES results in Bad-mediated apoptotic events. In addition, LY294002 inhibition of PI3K reduced 
phosphorylation of Bad at Ser136, which suggested PI3K was involved in the regulation of AKT in esophageal cancer cells. Caspase-9 induces cell death via mitochondria-mediated initiation of caspases (33). It has been reported that AKT is involved in the inactivation of caspase- 9 by phosphorylating caspase- 9 at Ser196 (19). Thus, caspase-9 is a target for AKT to prevent cells from apoptosis. Thus, VES suppresses AKT activity to downregulate phosphorylation of caspase-9 at Ser196, and then contributes to mitochondria-dependent apoptosis.

Previous studies indicate that PI3K/AKT/mTOR augment cancer cell growth and resistance to chemotherapeutics. The mTOR inhibitor rapamycin exhibits marked growth inhibitory effects against a broad range of types of human cancer $(34,35)$. The current study indicated that VES downregulated mTOR activity by suppressing phosphorylation of mTOR and inhibited its downstream effectors p70S6K and 4E-BP1. Furthermore, the results demonstrated that VES augmented suppression of rapamycin on mTOR and promoted apoptosis, and inhibited feedback activation of AKT induced by rapamycin, providing a combination therapeutic strategy for esophageal cancer using mTOR and VES.

In conclusion, the present study demonstrated that VES targeted PI3K/AKT signaling pathways and induced apoptosis in esophageal cancer cells. In addition, VES may work synergistically with inhibitors of members of the PI3K/AKT signaling pathways in order to more effectively control cancer cell survival and growth.

\section{Acknowledgements}

The authors would like to thank Summus Biological Technology Co., Ltd. (Harbin, China) for their technical support.

\section{References}

1. Montgomery EA, Bosman FT, Brennan P and Malekzadeh R: Oesophageal cancer. In: World Cancer Report 2014. Stewart BW and Wild CP (eds). International Agency for Research on Cancer, Lyon, pp528-543, 2014.

2. Lozano R, Naghavi M, Foreman K, Lim S, Shibuya K, Aboyans V, Abraham J, Adair T, Aggarwal R, Ahn SY, et al: Global and regional mortality from 235 causes of death for 20 age groups in 1990 and 2010: A systematic analysis for the Global Burden of Disease Study 2010. Lancet 380: 2095-2128, 2012.

3. Kelsen D, Daly JM, Kern SE, Levin B, Tepper JE and Van Cutsem E (eds.): Gastrointestinal Oncology: Principles and Practices. 2nd edition. Lippincott Williams \& Wilkins, Philadelphia, PA, p4, 2007.

4. Schottenfeld D and Fraumeni JF Jr (eds.): Cancer Epidemiology and Prevention. 3rd edition. Oxford University Press, Oxford, p697, 2006.

5. Ferri FF: Esophageal Tumors. In: Ferri's Clinical Advisor 2013. Mosby (Elsevier), Maryland Heights, MO, pp389-391, 2012.

6. National Cancer Institute: Cancer Statistics: SEER stat fact sheets, esophageal cancer. http://seer.cancer.gov/statfacts/html/ esoph.html. Accessed April 15, 2016.

7. Neuzil J, Tomasetti M, Mellick AS, Alleva R, Salvatore BA, Birringer $\mathrm{M}$ and Fariss MW: Vitamin $\mathrm{E}$ analogues: A new class of inducers of apoptosis with selective anti-cancer effect. Curr Cancer Drug Targets 4: 355-372, 2004.

8. Neuzil J, Wang XF, Dong LF, Low P and Ralph SJ: Molecular mechanism of 'mitocan'-induced apoptosis in cancer cells epitomizes the multiple roles of reactive oxygen species and Bcl-2 family proteins. FEBS Lett 580: 5125-5129, 2006.

9. Wang XF, Dong L, Zhao Y, Tomasetti M, Wu K and Neuzil J: Vitamin E analogues as anticancer agents: Lessons from studies with alpha-tocopheryl succinate. Mol Nutr Food Res 50: 675-685, 2006.
10. Malafa MP and Neitzel LT: Vitamin E succinate promotes breast cancer tumor dormancy. J Surg Res 93: 163-170, 2000.

11. Malafa MP, Fokum FD, Andoh J, Neitzel LT, Bandyopadhyay S, Zhan R, Iiizumi M, Furuta E, Horvath E and Watabe K: Vitamin E succinate suppresses prostate tumor growth by inducing apoptosis. Int J Cancer 118: 2441-2447, 2006.

12. Neuzil J: Vitamin E succinate and cancer treatment: A vitamin E prototype for selective antitumour activity. Br J Cancer 89: 1822-1826, 2003.

13. Quin J, Engle D, Litwiller A, Peralta E, Grasch A, Boley T and Hazelrigg S: Vitamin E succinate decreases lung cancer tumor growth in mice. J Surg Res 127: 139-143, 2005.

14. Annovazzi L, Mellai M, Caldera V, Valente G, Tessitore L and Schiffer D: mTOR, S6 and AKT expression inrelation to proliferation and apoptosis/autophagy in glioma. Anticancer Res 29: 3087-3094, 2009.

15. Falasca M: PI3K/Akt signaling pathway specific inhibitors: A novel strategy to sensitize cancer cells to anti-cancer drugs. Curr Pharm Des 16: 1410-1416, 2010.

16. McCubrey JA, Steelman LS, Chappell WH, Abrams SL, Wong EW, Chang F, Lehmann B, Terrian DM, Milella M, Tafuri A, et al: Roles of the Raf/MEK/ERK pathway in cell growth, malignant transformation and drug resistance. Biochim Biophys Acta 1773: 1263-1284, 2007.

17. Chang F, Lee JT, Navolanic PM, Steelman LS, Shelton JG, Blalock WL, Franklin RA and McCubrey JA: Involvement of PI3K/Akt pathway in cell cycle progression, apoptosis, and neoplastic transformation: A target for cancer chemotherapy. Leukemia 17: 590-603, 2003.

18. Datta SR, Dudek H, Tao X, Masters S, Fu H, Gotoh Y and Greenberg ME: Akt phosphorylation of BAD couples survival signals to the cell-intrinsic death machinery. Cell 91: 231-241, 1997.

19. Cardone MH, Roy N, Stennicke HR, Salvesen GS, Franke TF, Stanbridge E, Frisch S and Reed JC: Regulation of cell death protease caspase-9 by phosphorylation. Science 282: 1318-1321, 1998.

20. Mabuchi S, Ohmichi M, Kimura A, Hisamoto K, Hayakawa J, Nishio Y, Adachi K, Takahashi K, Arimoto-Ishida E, Nakatsuji Y, et al: Inhibition of phosphorylation of BAD and Raf-1 by Akt sensitizes human ovarian cancer cells to paclitaxel. J Biol Chem 277: 33490-33500, 2002.

21. Gibbons JJ, Abraham RT and Yu K: Mammalian target of rapamycin: Discovery of rapamycin reveals a signaling pathway important for normal and cancer cell growth. Semin Oncol 36 (Suppl 3): S3-S17, 2009.

22. Kline K, Yu W and Sanders BG: Vitamin E and breast cancer. J Nutr 134 (Suppl 12): S3458-S3462, 2004.

23. Yu W, Sanders BG and Kline K: RRR-alpha-tocopheryl succinate induction of DNA synthesis arrest of human MDA-MB-435 cells involves TGF-beta-independent activation of p21Waf1/Cip1. Nutr Cancer 43: 227-236, 2002.

24. Wan X, Harkavy B, Shen N, Grohar P and Helman LJ: Rapamycin induces feedback activation of Akt signaling through an IGF-1R-dependent mechanism. Oncogene 26: 1932-1940, 2007.

25. Jiang X, Sinnett-Smith J and Rozengurt E: Carbachol induces p70S6K1 activation through an ERK-dependent but Akt-independent pathway in human colonic epithelial cells. Biochem Biophys Res Commun 387: 521-524, 2009.

26. Asanuma K, Moriai R, Yajima T, Yagihashi A, Yamada M, Kobayashi D and Watanabe N: Survivin as a radioresistance factor in pancreatic cancer. Jpn J Cancer Res 91: 1204-1209, 2000.

27. Chawla-Sarkar M, Bae SI, Reu FJ, Jacobs BS, Lindner DJ and Borden EC: Downregulation of Bcl-2, FLIP or IAPs (XIAP and survivin) by siRNAs sensitizes resistant melanoma cells to Apo2L/TRAIL-induced apoptosis. Cell Death Differ 11: 915-923, 2004

28. Tamm I, Wang Y, Sausville E, Scudiero DA, Vigna N, Oltersdorf T and Reed JC: IAP-family protein survivin inhibits caspase activity and apoptosis induced by Fas (CD95), Bax, caspases, and anticancer drugs. Cancer Res 58: 5315-5320, 1998.

29. Yu W, Shun MC, Anderson K, Chen H, Sanders BG and Kline K: alpha-TEA inhibits survival and enhances death pathways in cisplatin sensitive and resistant human ovarian cancer cells. Apoptosis 11: 1813-1823, 2006.

30. Shun MC, Yu W, Park SK, Sanders BG and Kline K: Downregulation of epidermal growth factor receptor expression contributes to alpha-TEA's proapoptotic effects in human ovarian cancer cell lines. J Oncol 2010: 824571, 2010. 
31. Datta SR, Katsov A, Hu L, Petros A, Fesik SW, Yaffe MB and Greenberg ME: 14-3-3 proteins and survival kinases cooperate to inactivate $\mathrm{BAD}$ by $\mathrm{BH} 3$ domain phosphorylation. Mol Cell 6 : 41-51, 2000.

32. Hayakawa J, Ohmichi M, Kurachi H, Kanda Y, Hisamoto K, Nishio Y, Adachi K, Tasaka K, Kanzaki T and Murata Y: Inhibition of BAD phosphorylation either at serine 112 via extracellular signal-regulated protein kinase cascade or at serine 136 via Akt cascade sensitizes human ovarian cancer cells to cisplatin. Cancer Res 60: 5988-5994, 2000.
33. Li P, Nijhawan D, Budihardjo I, Srinivasula SM, Ahmad M, Alnemri ES and Wang X: Cytochrome $\mathrm{c}$ and dATP-dependent formation of Apaf-1/caspase-9 complex initiates an apoptotic protease cascade. Cell 91: 479-489, 1997.

34. Chan S: Targeting the mammalian target of rapamycin (mTOR): A new approach to treating cancer. Br J Cancer 91: 1420-1424, 2004.

35. Vignot S, Faivre S, Aguirre D and Raymond E: mTOR-targeted therapy of cancer with rapamycin derivatives. Ann Oncol 16: 525-537, 2005. 